\title{
Aroylketene dithioacetal chemistry: facile synthesis of 4-aroyl-3-methylsulfanyl-2-tosylpyrroles from aroylketene dithioacetals and TosMIC
}

\author{
H. Surya Prakash Rao* and S. Sivakumar
}

\author{
Full Research Paper \\ Address: \\ Department of Chemistry, Pondicherry University, Puducherry, 605 \\ 014, India \\ Email: \\ H. Surya Prakash Rao* - hspr@yahoo.com; S. Sivakumar - \\ shivazzin@yahoo.com \\ * Corresponding author
}

\section{Open Access}

Beilstein Journal of Organic Chemistry 2007, 3, No. 31 doi:10.1186/1860-5397-3-31

Received: 13 July 2007

Accepted: 28 September 2007

Published: 28 September 2007

(C) 2007 Prakash Rao and Sivakumar; licensee Beilstein-Institut.

License and terms: see end of document.

\begin{abstract}
The cycloaddition of the von Leusen's reagent ( $p$-tolylsulfonyl)methyl isocyanide (TosMIC) to $\alpha$-aroylketene dithioacetals (AKDTAs) in the presence of sodium hydride in THF at rt resulted in a facile synthesis of the 4-aroyl-3-methylsulfanyl-2tosylpyrroles 3 in good yield along with a minor amount of 4-[(4-methylphenyl)sulfonyl]-1-[(methylsulfanyl)methyl]-1Himidazole 4. This study lead to the synthesis of 2,3,4-trisubstiuted pyrroles having 1-naphthoyl/2-naphthoyl/ferrocenoyl/pyrenoyl scaffolds on C-4 of the pyrrole ring. In this transformation, the AKDTAs behave as a 3-(methylsulfanyl)-1-aryl-2-propyn-1-one $(\mathrm{ArCOC} \equiv \mathrm{CSMe}$ ) equivalent. Competition experiments clearly showed that the cycloaddition of TosMIC to "push-pull" alkenes like AKDTAs is slower compared to general $\alpha, \beta$-unsaturated carbonyl compounds.
\end{abstract}

\section{Background}

The $\alpha$-aroylketene dithioacetals (AKDTAs) 1 are useful threecarbon synthones extensively employed for the synthesis of a wide variety of heterocyclic compounds and also in several aromatic ring annulation reactions. [1,2] The AKDTAs are $\alpha, \beta$ unsaturated carbonyl compounds with two electron-donating alkylsulafanyl groups on one end and an electron-withdrawing aroyl group at the other end of the double bond, i.e., they are "push-pull" alkenes. Depending on the nucleophile and the reaction conditions either 1,2- or 1,4-necleophilc additions on $\mathbf{1}$ are possible. [3] Since alkylsulfanyl groups are good leaving groups, subsequent to the attack of a nucleophile, one of the alkylsulfanyl groups of the intermediate leave to regenerate the conjugated system. Being polarized alkenes the AKDTAs also react with bi-functional molecules having nucleophilic and electrophilic centers to furnish cyclic compounds. We have recently synthesized a combinatorial library of 3-aroylcoumarins by the reaction of 2-hydroxyarylaldehydes and the AKDTAs in presence of a catalytic amount of piperidine in THF. [4] Notwithstanding the popularity of AKDTAs in the synthesis of heterocyclic systems, examples of their participation in the cycloaddition reactions are rare. In continuation of our interest on ketene acetals [5-7] we considered that 1,3dipolar cycloaddition of the anion generated from the von Leusen's reagent ( $p$-tolylsulfonyl)methyl isocyanide (TosMIC) 2 to AKDTAs 1 could lead to 2,3,4-trisubstituted pyrroles having an aroyl moiety located on $\mathrm{C}-4$. Von Leusen's and 
others have amply demonstrated that the cycloaddition of TosMIC to the alkenes having strong electron-withdrawing groups (Michael acceptors) followed by loss of TosOH provide 3,4-disubstituted pyrroles in excellent yield. [8-10] Similarly, the reaction of TosMIC with activated alkynes afford trisubstituted pyrroles. However, the scope of pyrrole synthesis via cycloaddition of TosMIC to the "push-pull" alkenes is not well explored. We reasoned that, in the event of cycloaddition taking place between TosMIC and AKDTAs, the intermediate from the reaction would have three good leaving groups, namely, two methylsulfanyl and a tosyl. The release of one of the methylsulfanyl group could afford trisubstituted pyrroles having C-4 aroyl group. In such an outcome, the AKDTA substrates behave as a 3-(methylsulfanyl)-1-aryl-2-propyn-1one $(\mathrm{ArCOC} \equiv \mathrm{CSMe})$ equivalent. We report herein realization of the idea for the synthesis of trisubstituted pyrroles $\mathbf{3}$ from AKDTAs 1 and TosMIC 2. The pyrrole is one of the fundamental heterocycles. Its structure is widely found in many biological molecules. Naturally, there is a continuous interest to develop new synthesis of pyrroles. [11-13] Moreover, the target molecules of the present study, namely, 2,3,4-trisubstiuted pyrroles incorporate cannabinoid 3-aroylpyrrole structural motif [14] and that of some photo activators. [15] A recent report from Ila and co-workers on the use of some isocyanides for the syntheses of trisubstituted pyrroles prompts us to disclose our efforts in this area. [16]

\section{Results and Discussion}

The cycloaddition of TosMIC 2 to 3,3-di(methylsulfanyl)-1phenyl-2-propen-1-one 1a was taken as a test case to evaluate the cycloaddition and to arrive at the optimal reaction conditions. The cycloaddition of $\mathbf{2}$ to $\mathbf{1 a}$ took place smoothly in the presence of $\mathrm{NaH}$ in THF at rt to furnish [5-[(4-methylphenyl) sulfonyl]-4-(methylsulfanyl)-1H-3-pyrrolyl](phenyl)methanone 3a in 92\% yield (Scheme 1 and Table 1). The cycloaddition did not take place when piperidine in THF or $\mathrm{K}_{2} \mathrm{CO}_{3}$ in acetone reflux was employed. However, it is to be noted that when Ila and coworkers employed NaH/THF for the cycloaddition of ethyl isocyanoacetate to AKDTA 1a only $20 \%$ yield of the desired cycloadduct was obtained. [16] Near quantitative yield $(92 \%)$ in our reaction indicates higher reactivity of NaH/THF with TosMIC. Two singlets at $\delta 2.23$ and $\delta 2.42 \mathrm{ppm}$ in the ${ }^{1} \mathrm{H}$ NMR spectrum of 3a assignable for methyls of SMe and tosyl groups respectively served as diagnostic signals. As anticipated the ${ }^{13} \mathrm{C}$ NMR spectrum of $\mathbf{3 a}$ displayed fifteen signals, with a diagnostic signal at $\delta 127.9 \mathrm{ppm}$ assignable to pyrrole C-5.

Scheme 1: Cycloaddition of TosMIC to AKDTAs provide 2,3,4-trisub-
stituted pyrroles 3 and imidazole 4.

Careful examination of the reaction mixture from the reaction of TosMIC with 1 revealed the presence of a minor product which was characterized as 4-[(4-methylphenyl)sulfonyl]-1[(methylsulfanyl)methyl]-1H-imidazole 4 on the basis of its spectral and analytical data (Scheme 1 and Table 1). Previously, van Leusen's studied the base induced decomposition of TosMIC in $\mathrm{K}_{2} \mathrm{CO}_{3}$ in MeOH-DME or $\mathrm{NaH}$ in DME and found that one of the decomposition product was 4-[(4-methylphenyl)sulfonyl]-1-[(4-methylphenyl)sulfonyl]methyl-1 $H$ imidazole 5 (Scheme 2). [17,18] The imidazole 4 isolated in the present study could arise by substitution of tosyl group in $\mathbf{5}$ with methylsulfanyl group by in situ nucleophilic attack of methylsulfanyl anion. Yield of the side-product 4 increased at the cost of the desired pyrroles 3 when the reaction was conducted in THF reflux.

The cycloaddition of TosMIC $\mathbf{2}$ to a variety of AKDTAs $\mathbf{1 b}-\mathbf{g}$ furnished good yield of new pyrroles $\mathbf{3} \mathbf{b}-\mathbf{g}$ in a facile manner, which demonstrated generality of the transformation (Scheme 1, Table $1 \&$ Figure 1). The analytical and spectral data of $\mathbf{3 b - g}$ compared well with the parent pyrrole 3a. In each case, desired pyrroles $\mathbf{3 b}-\mathbf{g}$ were separated from minor amount of the

\begin{tabular}{|c|c|c|c|c|c|c|}
\hline Entry & $\mathrm{Ar}$ & AKDTA 1 & Pyrrole 3 & Time $(\mathrm{h})$ & Yield (\%) of $\mathbf{3}^{a}$ & Yield $(\%)$ of $4^{b}$ \\
\hline 1 & $\mathrm{C}_{6} \mathrm{H}_{5}$ & $1 \mathrm{a}$ & $3 a$ & 8 & 92 & 3 \\
\hline 2 & $4-\mathrm{CH}_{3} \mathrm{C}_{6} \mathrm{H}_{4}$ & $1 b$ & $3 b$ & 8 & 90 & 4 \\
\hline 3 & $4-\mathrm{ClC}_{6} \mathrm{H}_{4}$ & $1 \mathrm{c}$ & $3 c$ & 6 & 87 & 5 \\
\hline 4 & $4-\mathrm{C}_{6} \mathrm{H}_{5} \mathrm{C}_{6} \mathrm{H}_{4}$ & $1 d$ & $3 d$ & 5 & 93 & 3 \\
\hline 5 & $1-\mathrm{C}_{10} \mathrm{H}_{7}$ & $1 e$ & $3 e$ & 5 & 87 & 4 \\
\hline 6 & $2-\mathrm{C}_{10} \mathrm{H}_{7}$ & $1 f$ & $3 f$ & 6 & 85 & 5 \\
\hline 7 & $\mathrm{C}_{5} \mathrm{H}_{5} \mathrm{FeC}_{5} \mathrm{H}_{4}$ & $1 \mathrm{~g}$ & $3 g$ & 9 & 78 & 12 \\
\hline
\end{tabular}

a yield is based on the AKDTAs used. ${ }^{b}$ yield is based on TosMIC used. 


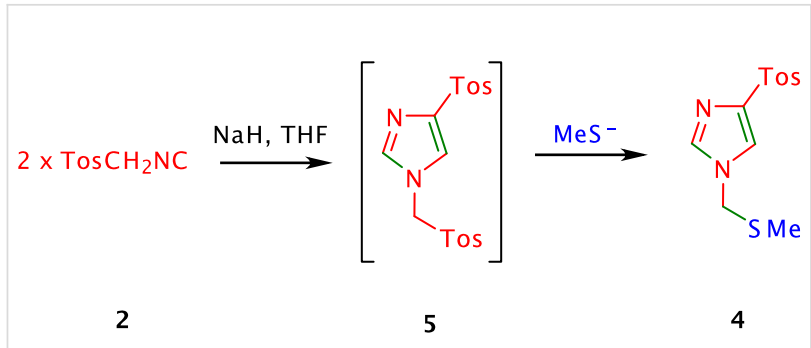

Scheme 2: Base induced dimerization of TosMIC to furnish imidazole

imidazole 4 contaminant by column chromatography. The structure of $\mathbf{3 b}$ was confirmed on the basis of the single crystal $\mathrm{X}$-ray structure analysis (deposited with Cambridge Crystallographic Data Center (CCDC); deposition No. 628766). The structure of AKDTAs $\mathbf{1 b}$-g appears to have no major influence on the observed yield of the pyrroles 3 . The AKDTAs having electron donating (4-Me, $\mathbf{1 b}$ or ferrocene 1g), or electron-withdrawing groups (4-Cl, $\mathbf{1 c}$ or 4-Ph, 1d) furnished corresponding pyrroles in good and comparable yield. The 2,3,4-trisubstituted pyrroles having 4-phenylbenzoyl (3d), 1-naphthoyl (3e), 2-naphthoyl (3f) and ferrocenoyl (3g) groups are to be noted for the variety of pyrrole derivatives prepared (Figure 1). It is interesting to note that [5-[(4-methylphenyl)sulfonyl $]-4-$ (methylsulfanyl)-1H-3-pyrrolyl](1-naphthyl)methanone $\mathbf{3 e}$ has the structural motif of some of the cannabinoids. [14]

In continuation, and by following the method presently developed, the trisubstituted pyrrole 7 having pyrenoyl substituent was synthesized from AKDTA 6 (Scheme 3).

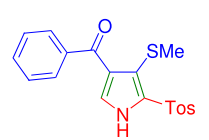

3a

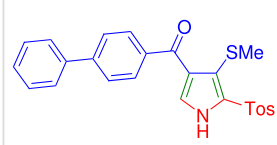

$3 d$

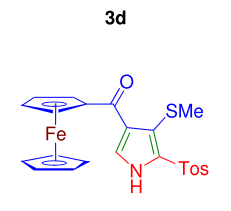

$3 g$

Figure 1: Structure of 2,3,4-trisubstituted pyrroles 3a-g synthesized in this study.
Initially, 1-acetylpyrene $\mathbf{5}$ was transformed to hitherto unknown pyrene based AKDTA 6 by reaction with carbon disulfide and sodium tert-butoxide followed by alkylation with dimethyl sulfate. The reaction of TosMIC 2 with AKDTA 6 provided the trisubstituted pyrrole 7 in excellent yield. As anticipated, the ${ }^{1} \mathrm{H}$ NMR spectrum of pyrenoylpyrrole 7 exhibited a doublet for $\mathrm{C} 2 '-\mathrm{H}$ of pyrene unit as a doublet at $\delta 8.37 \mathrm{ppm}$ and a singlet at $\delta 7.06 \mathrm{ppm}$ for $\mathrm{C} 5-\mathrm{H}$ of the pyrrole unit.

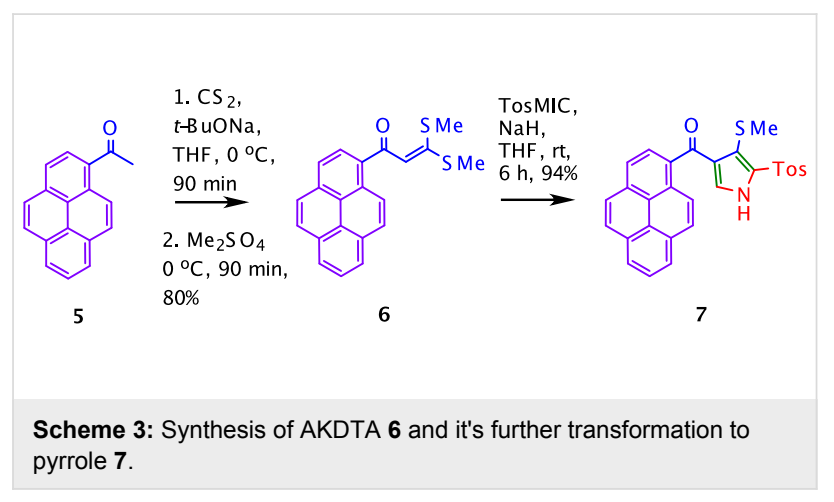

Next we have studied the cycloaddition reaction of TosMIC to (4E)-1,1-di(methylsulfanyl)-5-phenyl-1,4-pentadien-3-one 8 [19] a molecule having two double bonds - one between C-1 and C-2 is flanked by the two electron-donating methylsufanyl and the electron-withdrawing carbonyl group and the other one between C-4 and C-5 is flanked by the electron-withdrawing carbonyl and phenyl groups (Scheme 4). The former double bond is a "push-pull" type and is more polarized compared to the latter double bond. This reaction provided 3,3-di(methylsulfanyl)-1-(4-phenyl-1H-3-pyrrolyl)-2-propen-1-one 9 exclusively (Scheme 3). Above reaction demonstrated that TosMIC 2 reacts with a double bond flanked by two electron-withdrawing groups in preference over the "push-pull" double bond with electron donating and withdrawing groups. To substantiate the reasoning, competitive cycloaddition experiments between 1 mmol each of AKDTA 1a and phenyl vinyl ketone 10 or AKDTA 1a and (E)-4-phenyl-3-buten-2-one 11 with $1 \mathrm{mmol}$ of TosMIC 2 were conducted in the presence of $\mathrm{NaH}$ in THF and in each case known pyrroles 12 [20] and 13 [21,22] were obtained exclusively (Scheme 5).

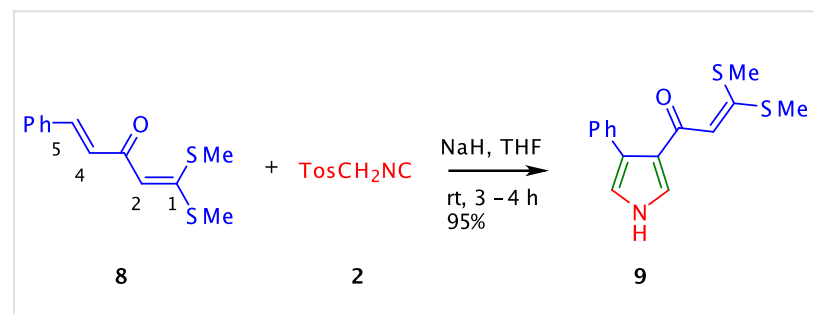

Scheme 4: Regio-selectivity in the reaction of TosMIC with 8. 
<smiles>CS/C(C)=C/C(=O)Br</smiles><smiles>C=CC(=O)c1ccccc1</smiles>

$\longrightarrow$ $\mathrm{NaH}, \mathrm{THF}$

10

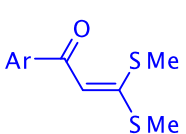

1a and

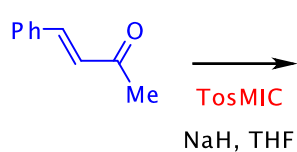

11

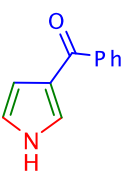

12

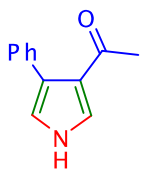

13
Scheme 5: Competition experiments involving one mmol each of TosMIC with AKDTA 1a and phenyl vinyl ketone $\mathbf{1 0}$ or with AKDTA 1a and $(E)$-4-phenyl-3-buten-2-one 11 to provide pyrroles 12 and 13 respectively.

\section{Conclusion}

In summary, we reported a facile synthesis of 2,3,4-trisubstituted pyrroles having a variety of aroyl groups in C-4 position from AKDTAs and TosMIC. The competition experiments demonstrated that TosMIC reacts with electron deficient olefins in preference to "push-pull" alkenes. Future works will concentration on desulfuration of the methylsulfanyl group in $\mathbf{3}$ to generate 3,5-disubstituted pyrroles or oxidation of methylsulfanyl group to methylsulfonyl group followed by nucleophilic displacement to generate pyrroles of structural diversity.

\section{Experimental}

"See the Supporting Information File 1 for the full experimental data"

\section{Supporting Information}

\section{Supporting Information File 1}

Supporting information of Experimental procedures and NMR spectra $\left({ }^{1} \mathrm{H}\right.$ and $\left.{ }^{13} \mathrm{C}\right)$ of all the new compounds. [http://www.beilstein-journals.org/bjoc/content/ supplementary/1860-5397-3-31-S1.doc]
2. Dieter, R. K. Tetrahedron 1986, 42, 3029-3096. doi:10.1016/S00404020(01)87376-2

3. Ila, H.; Junjappa, H.; Mahanta, P. K. In Progress in Heterocyclic Chemistry; Gribble, G. W.; Gilchrist, T. L., Eds.; Pergamon: Oxford, UK, 2001; Vol. 13, Chapter 1, pp 1-24.

4. Rao, H. S. P.; Sivakumar, S. J. Org. Chem. 2006, 71, 8715-8723. doi:10.1021/jo061372e

5. Rao, H. S. P.; Sivakumar, S. J. Org. Chem. 2005, 70, 4524-4527. doi:10.1021/jo050308e

6. Rao, H. S. P.; Sakthikumar, L.; Vanitha, S.; Sivakumar, S. Tetrahedron Lett. 2003, 44, 4701-4704. doi:10.1016/S0040-4039(03)01086-4

7. Rao, H. S. P.; Sakthikumar, L.; Shreedevi, S. Sulfur Lett. 2002, 207-218. doi:10.1080/02786110214497

8. Reddy, V. V. R. Synlett 2005, 363-364. doi:10.1055/s-2004-837237

9. Tandon, V. K.; Rai, S. Sulfur Rep. 2003, 24, 307-385. doi:10.1080/ 0196177031000116746

10. van Leusen, D.; van Leusen, A. M. Org. React. 2001, 57, 417-666.

11. Jones, R. A.; Bean, G. P. In The Chemistry of Pyrroles; Academic Press: London, 1977; pp 1-5.

12. Sundberg, R. J. In Comprehensive Heterocyclic Chemistry; Katritzky, A. R.; Rees, C. W., Eds.; Pergamon: Oxford, 1984; Vol. 4, pp 313-376.

13. Sundberg, R. J. In Comprehensive Heterocyclic Chemistry II; Kartritzky, A. R.; Rees, C. W., Eds.; Pergamon: Oxford, 1996; Vol. 2, pp 119-206.

14. Lainton, J. A. H.; Huffman, J. W.; Martin, B. R.; Compton, D. R. Tetrahedron Lett. 1995, 36, 1401-1404. doi:10.1016/0040-4039(95) 00016-6

15. Perez-Prieto, J.; Galian, R. E.; Miranda, M. A. Mini-Rev. Org. Chem. 2006, 3, 117-135. doi:10.2174/157019306776819226

16. Misra, N. C.; Panda, K.; Ila, H.; Junjappa, H. J. Org. Chem. 2007, 72, 1246-1251. doi:10.1021/jo062139j

17. van Leusen, A. M.; Wildeman, J.; Oldenziel, O. H. J. Org. Chem. 1977, 42, 1153-1159. doi:10.1021/jo00427a012

18. Kanaza, C.; Kamijo, S.; Yamamoto, Y. J. Am. Chem. Soc. 2006, 128, 10662-10663. doi:10.1021/ja0617439

19. Myrboh, B.; Asokan, C. V.; Ila, H.; Junjappa, H. Synthesis 1984, 50-51. doi:10.1055/s-1984-30728

20. Simchen, G.; Majchrzak, M. W. Tetrahedron Lett. 1985, 26, 5035-5036. doi:10.1016/S0040-4039(01)80846-7

21. Kartritzky, A. R.; Cheng, D.; Musgarave, R. P. Heterocycles 1997, 44, 67-70.

22. van Leusen, A. M.; Siderius, H.; Hoogenboom, B. E.; van Leusen, D. Tetrahedron Lett. 1972, 5337-5340. doi:10.1016/S0040-4039(01) 85244-8

23. D'Souza, L. J.; Maitra, U. J. Org. Chem. 1996, 61, 9494-9502. doi:10.1021/jo9607525

\section{Acknowledgments}

HSPR thanks UGC, UGC-SAP, CSIR and DST-FIST for financial assistance. SS thanks CSIR for awarding SRF. We thank IACS, Kolkata, and SAIC, IIT, Chennai for recording spectra.

\section{References}

1. Junjappa, H.; Ila, H.; Asokan, C. V. Tetrahedron 1990, 46, 5423-5506. doi:10.1016/S0040-4020(01)87748-6 


\section{License and Terms}

This is an Open Access article under the terms of the Creative Commons Attribution License

(http://creativecommons.org/licenses/by/2.0), which permits unrestricted use, distribution, and reproduction in any medium, provided the original work is properly cited.

The license is subject to the Beilstein Journal of Organic Chemistry terms and conditions:

(http://www.beilstein-journals.org/bjoc)

The definitive version of this article is the electronic one which can be found at:

doi:10.1186/1860-5397-3-31 